\title{
Investigation of the influence of contact friction forces in tests on the strength of compressing wall materials
}

\author{
Nataliya Lukinova ${ }^{1,{ }^{*}}$, Andrey Matrosov ${ }^{1}$, Irina Serebryanaya ${ }^{2}$, Yuliya Terekhina $^{2}$, Dariya Nizhnik $^{1}$ \\ ${ }^{1}$ Don State Technical University, Rostov-on-Don, Russia \\ ${ }^{2}$ Academy of Architecture and Construction, Don State Technical University, Rostov-on-Don, Russia
}

\begin{abstract}
The results of the experiment are presented, which estimate the effect of the support friction in standard tests on axial compression on the output strength characteristics of the hand-formed brick. The effect of surface parameters on the compressive strength was established. The optimal shape and dimensions of the samples, as well as the method of preparation of their surfaces, were determined.
\end{abstract}

\section{Introduction}

Axial compression testing is the main type of strength control of most building materials. The results of these tests are laid in the designs of buildings and structures, from which it follows that the errors of these experiments should be reduced to a minimum. When analyzing the results of tests of building materials on compressive strength, it is assumed that these values were obtained under conditions of a linear stress state, in reality, a volumetric stress state is realized in tests, which is confirmed by the nature of the destruction of the samples [1-2]. The volumetric stress state is due to the presence of frictional contact forces between the sample and the press plates, which in turn leads to an overestimation of the strength parameters [3-4]. This explains the practical relevance and relevance of the chosen topic, since a reliable estimate of compressive strength is a necessary condition for correct calculation of buildings and structures. An analysis of the results of experiments aimed at investigating the effect of frictional contact forces in compressive strength tests will make it possible to develop an optimal test method that ensures that the results obtained are close to the true value of the measurand [5].

\section{Methods of research}

The tests were carried out on tested certified equipment. In order to measure the destructive load, a hydraulic press P-125 equipped with a torsion dynamometer was used. For the production of samples representing the halves of the product, the PRG-1-50K press was used, which is a hydrostatic force multiplier with a manual drive.

The bearing face (bed) of ceramic bricks always has significant deviations from flatness, which does not ensure the uniformity of the distribution of load on the entire plane of the sample when tested for compressive strength [6]. Therefore, in the preparation of samples for testing, the surfaces are leveled, which in the structure and, accordingly, during testing, are located perpendicular to the direction of the axis of the compressive load.

According to the current legislation of the Russian Federation in accordance with GOST 530-2012 "Brick and ceramic stone. General specifications" preparation of bearing faces of brick samples for acceptance testing is performed by grinding. The deviation from the flatness of the bearing surfaces of the test specimens shall not exceed $0.1 \mathrm{~mm}$ for every $100 \mathrm{~mm}$ of length. The nonparallelism of the support surfaces of the test specimens (the height difference measured by the four vertical edges) should not be more than $2 \mathrm{~mm}$ [7]. It should be noted that the surface of the hand-formed brick, due to the special features of the production, is characterized by great heterogeneity, is characterized by the presence of grooves, cracks, corrugations, bugholes and spallings that are not defects, and serving as necessary means for implementing the decorative function of the product and imitating the ancient brick laying [8-9]. Thus, it is logical to assume that as a result of grinding, the contact surface of the tested samples will be substantially changed, which in turn will inevitably lead to distortion of the measurement results and overestimation of the strength characteristics of the batch. It is also permissible to apply other methods of leveling the reference surfaces of samples when carrying out acceptance testing, provided there is a correlation between the results obtained by different methods, as well as the availability of verification of information that is the basis for such a connection [10].

Regarding the European legislation, in accordance with EN 772-1: 2014 "Methods of test for masonry units Part 1. Determination of compressive strength" of the surface of the test specimen is made to conform to the requirements for flatness and straightness. The deviation from the flatness of the loaded surfaces of the sample

\footnotetext{
* Corresponding author: lukinova-n@ya.ru
} 
(article or fragment) should not exceed $0.1 \mathrm{~mm}$ for every $100 \mathrm{~mm}$ of length. The deviation from the straightness of the upper surface of the test specimen should not exceed $1 \mathrm{~mm}$ for every $100 \mathrm{~mm}$ of length. However, with a strong change in the contact surfaces due to grinding, they are leveled using a cement-sand mortar [11-12]. In our opinion, this method also has a significant drawback, since it leads to the appearance of a mechanical interaction of the product with a grout based on the penetration of the grout in bugholes with the formation of a locking engagement. And this is the same as in the case of grinding will lead to an additional increase in strength.

Other methods for preparing a brick surface for compressive strength tests are known, in particular in the Netherlands, in accordance with NEN 6790: 1991, two whole bricks are used in the tests, using felt liners between them and the support surfaces of the felt [13]. In the USA, brick tests are performed in accordance with ASTM C6703a. According to the specified standard, it is possible to use two methods of surface preparation: leveling with gypsum mortar or sulfur concrete solution [14]. In India, however, there is no standard for test methods for bricks, but traditionally one whole brick is used for testing, placed between two plywood sheets [15].

Based on the analysis of the domestic and foreign regulatory framework, the selection of methods for preparing the surfaces for the experiment was made.

For grinding the samples, a belt grinder MAKITA 9404 was used.

To prepare the surface of the remaining samples for testing, the following materials were used:

- a cement-sand mortar consisting of equal parts of cement grade 400 and sand sieved through a sieve with mesh No. 1,25 (V / C =0,40), layer thickness $5 \mathrm{~mm}$;

- gypsum mortar consisting of gypsum grade G-16, layer thickness $5 \mathrm{~mm}$, water-gypsum ratio 0.35 ;

- $5 \mathrm{~mm}$ technical thin-wool felt in two layers;

- plywood birch 9mm.

The shapes and sizes of the samples, which are acceptable in accordance with different standards, are also unequal. In accordance with Russian legislation, until 2012, when determining the compressive strength, it was allowed to use two halves of bricks, in particular those formed after the bending test, stacked on opposite surfaces with each other [16-17]. In accordance with the amendments introduced in 2012, it is allowed to use only whole bricks, laid on top of each other. According to the European standard, a sample consisting of one whole product is used. An exception is made only if, after grinding, the height of the sample is less than $40 \mathrm{~mm}$ or the ratio of height to width is less than 0.4 , a composite sample is made by stacking the products one on top of another without using a solution, a connecting material or a separation layer. And, finally, under American law, the test samples represent single halves of bricks. Samples should be obtained by any method that allows the separation of bricks into two equal parts without cracks and destruction.

Based on the results of the analysis of the domestic and foreign regulatory framework, a sample of methods for preparing samples for the experiment was made.

\section{Experimental results}

Based on the tests performed, a summary table of results was compiled (Table 1).

Table 1. Results of the determination of compressive strength.

\begin{tabular}{|c|c|c|c|c|c|c|c|}
\hline $\begin{array}{c}\text { Alignment } \\
\text { method }\end{array}$ & $\begin{array}{l}\text { Number } \\
\text { of } \\
\text { products } \\
\text { for one } \\
\text { sample }\end{array}$ & $\begin{array}{l}\mathrm{R}_{1} \\
\mathrm{MPa}\end{array}$ & $\begin{array}{c}\mathrm{R}_{2} \\
\mathrm{MPa}\end{array}$ & $\begin{array}{c}\mathrm{R}_{3} \\
\mathrm{MPa}\end{array}$ & $\begin{array}{l}\mathrm{R}_{4} \\
\mathrm{MPa}\end{array}$ & $\begin{array}{c}\mathrm{R}_{5} \\
\mathrm{MPa}\end{array}$ & $\begin{array}{c}\text { Average } \\
\text { value } \mathrm{R}, \\
\mathrm{MPa}\end{array}$ \\
\hline \multirow{4}{*}{$\begin{array}{c}\text { Without } \\
\text { alignment }\end{array}$} & $\begin{array}{c}\text { two } \\
\text { whole }\end{array}$ & 11,957 & 13,252 & 16,622 & 12,959 & 12,697 & 13,497 \\
\hline & $\begin{array}{c}\text { two } \\
\text { halves }\end{array}$ & 18,296 & 19,362 & 15,636 & 16,064 & 17,261 & 17,323 \\
\hline & $\begin{array}{c}\text { one } \\
\text { whole }\end{array}$ & 18,781 & 16,027 & 14,766 & 17,179 & 20,998 & 17,550 \\
\hline & $\begin{array}{l}\text { one } \\
\text { half }\end{array}$ & 20,983 & 19,625 & 21,202 & 15,01 & 22,516 & 19,867 \\
\hline \multirow{3}{*}{\begin{tabular}{|} 
Alignment \\
with \\
cement- \\
sand \\
mortar
\end{tabular}} & $\begin{array}{c}\text { two } \\
\text { whole }\end{array}$ & 14,691 & 12,971 & 15,682 & 14,459 & 13,121 & 14,184 \\
\hline & $\begin{array}{c}\text { two } \\
\text { halves }\end{array}$ & 18,289 & 19,321 & 16,136 & 17,064 & 18,261 & 17,814 \\
\hline & $\begin{array}{c}\text { one } \\
\text { whole }\end{array}$ & 19,396 & 19,652 & 18,841 & 15,42 & 17,188 & 18,099 \\
\hline \multirow{2}{*}{$\begin{array}{l}\text { Grinding } \\
\text { alignment }\end{array}$} & $\begin{array}{c}\text { two } \\
\text { whole }\end{array}$ & 15,284 & 15,771 & 17,391 & 16,069 & 15,859 & 16,074 \\
\hline & $\begin{array}{c}\text { one } \\
\text { whole }\end{array}$ & 18,187 & 18,962 & 19,776 & 18,179 & 20,998 & 19,220 \\
\hline $\begin{array}{l}\text { Aligning } \\
\text { with } \\
\text { gypsum } \\
\end{array}$ & $\begin{array}{c}\text { one } \\
\text { whole }\end{array}$ & 20,166 & 19,991 & 21,533 & 16,011 & 21,215 & 19,783 \\
\hline \multirow{2}{*}{$\begin{array}{c}\text { Felt } \\
\text { Alignment }\end{array}$} & $\begin{array}{c}\text { two } \\
\text { whole }\end{array}$ & 10,809 & 10,073 & 10,268 & 7,862 & 9,573 & 9,717 \\
\hline & $\begin{array}{l}\text { two } \\
\text { halves }\end{array}$ & 10,882 & 11,276 & 12,372 & 11,47 & 11,409 & 11,481 \\
\hline $\begin{array}{c}\text { Plywood } \\
\text { Alignment }\end{array}$ & $\begin{array}{c}\text { one } \\
\text { whole }\end{array}$ & 16,129 & 18,944 & 15,139 & 16,961 & 19,933 & 17,421 \\
\hline
\end{tabular}

Based on the obtained results, it was established that in addition to the method of leveling the sample surface before the test, the size and shape of the sample exert a large influence on the compressive strength value. So, it is evident that, other things being equal, the samples consisting of two whole products show the least strength, regardless of the method of alignment. Further strength increases with decreasing dimensions of the supporting surfaces and reaches its peak on a sample consisting of one half of the product. This is clearly demonstrated in the diagram shown in Fig. 1. For its compilation, alignment methods were used, according to which the test results with the largest number of sample types were used. As for the stability of the results, the smallest range of data is characteristic of samples consisting of two halves of the product stacked on top of each other. This is due to the fact that this type of specimen in shape is most closely approximated to the shape of the cube. 
It is also worth noting that for all types of leveling, the average strength of samples consisting of two halves is almost equal to the strength of samples consisting of a single whole product, but the latter is less stable.

Thus, as the dimensions of the sample and the areas of the contact surfaces increase, the resistance decreases. The decrease in strength in large samples with the usual method of testing them should be explained by the diminishing influence of the support friction.

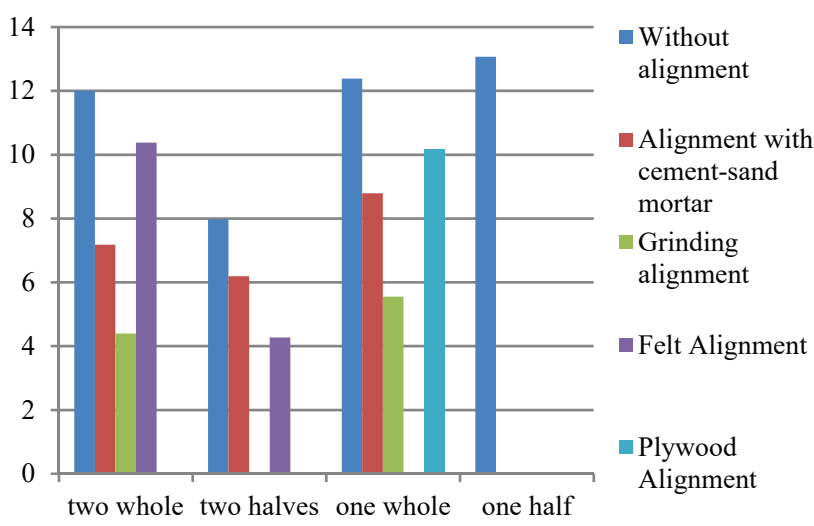

Fig. 1. Dependence of strength value on sample size and surface leveling method

In general, the lower the sample, the stronger the effect of the reference friction on the value of the time resistance to compression. Conversely, as the height of the sample increases, the transverse expansion of the latter becomes more free and the material reaches its ultimate strength under a lower load [18-19].

With regard to the method of leveling the surface, the samples aligned with the pads made of technical felt, regardless of shape and size, show less strength, compared with other methods of surface preparation, but are characterized by a smaller spread of values. When leveling with felt, often the sample splits along the entire length (Fig. 2). In other cases, des6rtuctions are presented by the scattering of the faces of the samples.
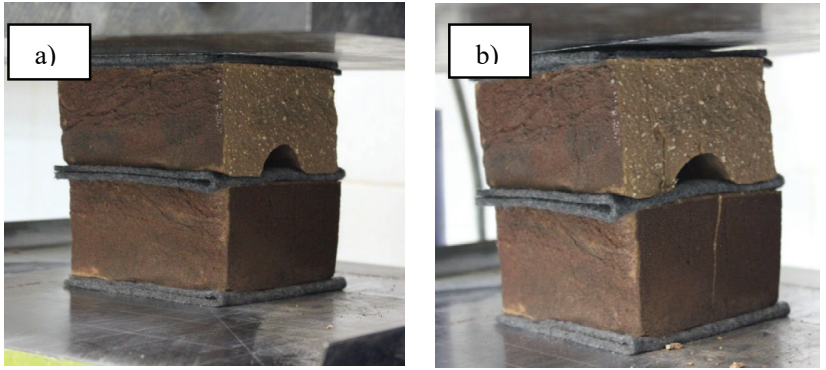

$\mathrm{a}$ - the sample before the test; $\mathrm{b}$ - sample after the test

Fig. 2. The nature of the destruction of a sample lined with felt pads

As can be seen from the figure, the through crack passes through the entire sample exactly in the middle. Such results are associated with a decrease in the influence of frictional force, since the felt is smoother than the untreated surface of the hand-formed brick or the cement solution. Cracks are formed in the sample, parallel to the direction of compression (perpendicular to the bed). In this case, friction no longer prevents the development of transverse deformations of the end faces of the sample, and they increase until a break in the brick occurs [20-21]. Accordingly, destruction from the break occurs at a much lower compressive load than shear failure. In other cases, friction delays transverse deformations of the sample (transverse expansion) and does not allow them to develop up to the limiting value corresponding to the rupture.

Along with this, the increased strength parameters of the samples, leveled by means of a cement-sand mortar, are caused by the mechanical interaction of the solution with the surface of the sample, based on the penetration of the first into the cavities with the formation of a locking engagement.

The high strength of the samples, leveled by means of grinding, is due to a significant change in their contact surface, which also makes it difficult to form an objective quality assessment.

\section{Results of the numerical experiment}

To verify the conclusions of the full-scale experiment, finite element modeling of the stressed-deformed state of the hand-formed brick was carried out using the ANSYS 17.2 software package (Fig. 3).

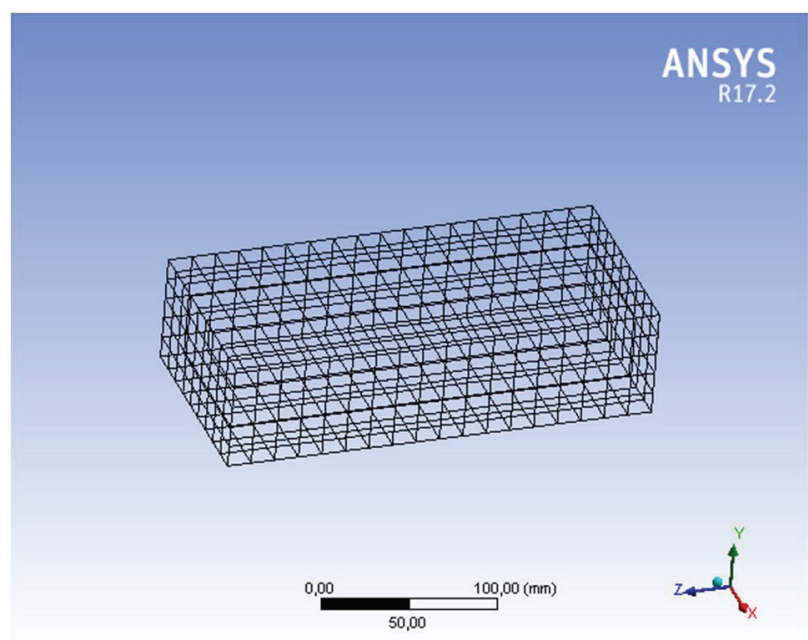

Fig. 3. Finite Element Model

Modeling was carried out taking into account various ways of preparing the surface of samples for testing, as well as various types of samples in shape and size.

The results of the numerical experiment very well agree with the field experiment, which shows the correctness of mechanical model selection.

\section{Conclusion}

On the basis of the conducted research, the effect of contact frictional forces on the output characteristics of 
the strength of the hand-formed brick was established. It is shown that with standard tests of bricks in accordance with GOST 530-2012 a systematic error arises due to the appearance of a three-dimensional stress state. This is confirmed by the nature of the destruction of the samples. The volumetric stress state is due to the presence of frictional contact forces between the sample and the press plates, which in turn leads to an overestimation of the strength parameters. According to the results of the experiment, the most optimal method of preparing surfaces for testing is the use of linings from technical felts. The tests themselves are recommended to be carried out on samples consisting of two halves of the product laid on top of each other.

The results of the numerical experiment agree well with the results of the field experiment, which indicates that the model constructed in ANSYS 17.2 reliably describes the real picture and can be used as a basis for further research.

\section{References}

1. I.A. Serebryanaya, J.V. Terehina, N.A. Lukinova, International Conference PHENMA 2016, Surabaya, Indonesia, 237 (2016)

2. S.S Kirilenko, Herald of Civil Engineers, 2(23), 48$50(2010)$

3. V.Z. Vasiliev, S.S Kirilenko, III International Scientific Conference "Actual Problems of Mechanics and Mechanical Engineering", Almaty, 142-145 (2009)

4. V.V. Pangaev, Proceedings of high schools. Building, 10, 99-106 (2004)

5. N.A. Lukinova, I.A. Serebryanaya, Young researcher of the Don, 2(2), 1-3 (2016)

6. N.A. Lukinova, A.A. Matrosov, D.A. Nizhnik, I.A. Serebryanaya, J.V. Terehina, $V$ International Scientific and Practical Conference "Innovative Technologies in Science and Education", Divnomorskoe, 179-181 (2017)

7. GOST 8462-85 Wall materials. Methods for determination of compressive and flexural strengths (1985)

8. V.A. Khatlamadgiyan, J.V. Terehina, A.V. Kotlyar, XX International Scientific and Practical Conference "Modern technology and technology", Rostov-on-Don, 113-114 (2014)

9. J.V. Terehina, V.D. Kotlyar, Yu.I. Nebegco, XVII International Scientific and Practical Conference "Modern Technologies and Technologies", Rostovon-Don, 165-166 (2014)

10. GOST 530-2012 Bricks and stone, ceramic. General specifications (2012)

11. EN 771-1:2009 Specification for masonry units Part 1. Clay masonry units (2009)
12. EN 772-1:2014 Methods of test for masonry units Part 1. Determination of compressive strength (2014)

13. NEN 6790:1991 Masonry structures - Basic requirements and determination methods (1991)

14. ASTM C67-03a Standard Test Methods for Sampling and Testing Brick and Structural Clay Tile (2003)

15. N.A. Lukinova, I.A. Serebryanaya, J.V. Terehina, International scientific and practical conference "Modern condition and prospects of development of engineering and environmental systems, building technologies, materials and quality in construction", Rostov-on-Don, 396-397 (2015)

16. GOST 530-2007 Bricks and stone, ceramic. General specifications (2007)

17. N.A. Lukinova, I.A. Serebryanaya, J.V. Terehina, International Scientific and Practical Conference "Construction and Architecture - 2016", Rostov-onDon, 256-259 (2016)

18. A.A. Matrosov, I.A. Serebryanaya, N.A. Lukinova, T.N. Brovko, XII all-russian school-seminar "Mathematical modeling and biomechanics in the modern university", Divnomorskoe, 92-93 (2017)

19. L.M. Abramov, A.V. Orehov, I. L. Abramov, Industrial and civil construction, 1, 58 (2012)

20. A.A. Mungin, Modern technologies - transport, 2, 64-67 (2013)

21. A.A. Mungin, International Scientific and Practical Conference "Education and Science: Current State and Prospects for Development", Tambov, 86-90 (2013) 